\title{
Inhaled synthetic surfactant abolishes the early allergen-induced response in asthma
}

\author{
K.S. Babu*, D.A. Woodcock ${ }^{\#}$, S.E. Smith*, J.N. Staniforth ${ }^{\Uparrow}$, S.T. Holgate*, J.H. Conway*
}

Inhaled synthetic surfactant abolishes the early allergen-induced response in asthma. K.S. Babu, D.A. Woodcock, S.E. Smith, J.N. Staniforth, S.T. Holgate, J.H. Conway. (C) ERS Journals Ltd 2003.

ABSTRACT: Allergen-induced inhibition of pulmonary surfactant in asthma may promote airway oedema and consequently potentiate the severity of the asthmatic response. A randomised, single-blind, cross-over study of an inhaled synthetic phospholipid dry-powder surfactant (Pumactant) was conducted in atopic, asthmatic subjects with previously documented early and late asthmatic responses (EAR and LAR) to an inhaled allergen. This was conducted to evaluate the role of exogenous surfactant administration on EAR and LAR. A total of seven subjects had complete evaluable data and received the full dose of Pumactant.

Asthmatic subjects inhaled two separate doses of $400 \mathrm{mg}$ Pumactant prior to an allergen exposure. The first dose was administered $8 \mathrm{~h}$ in advance and the second dose $30 \mathrm{~min}$ in advance. The dosage occurred through a purpose-built administration device. This was followed by a standard bronchial-provocation test, and forced expiratory volume in one second (FEV1) was measured at regular intervals over a 10-h period.

Pumactant was well tolerated and, surprisingly, abolished the EAR but not the LAR in all seven subjects. The mean area under the curve between $0-2 \mathrm{~h}$ (EAR) following bronchial provocation test was 0.08 for the Pumactant treatment group (PT) and 13.29 for the no treatment (NT) group. The maximum drop in FEV1 for EAR was $4.19 \%$ and $23.98 \%$ in the PT and the NT group, respectively.

The demonstration of inhibition of the early asthmatic response by exogenous surfactant, provides the first evidence that pulmonary surfactant dysfunction may also contribute to the very early asthmatic response to allergen. Exogenous surfactant administration could serve as a useful adjunct in controlling the early allergen-induced symptoms in patients with allergic asthma.

Eur Respir J 2003; 21: 1046-1049.
*Division of Infection, Inflammation and Repair, School of Medicine, Southampton General Hospital, Southampton, "Britannia Pharmaceuticals Limited, Surrey and ${ }^{\top}$ Dept of Pharmacy and Pharmacology, University of Bath, UK.

Correspondence: K.S. Babu, Mailpoint 810 Level D, Centre Block, Southampton General Hospital, Tremona Road, Southampton, SO16 6YD, UK.

Fax: 442380701771

E-mail: ksb@soton.ac.uk

Keywords: Allergen provocation

asthma

asthmatic response

exogenous surfactant

Pumactant

Received: September 22002

Accepted after revision: January 232003

D.A.Woodcock is an employee of Britannia Pharmaceuticals Ltd, the manufacturer of Pumactant. In addition J.H. Conway and J.N. Staniforth are scientific advisors to Britania Pharmaceuticals Ltd. The other authors have no conflict of interest.
Endogenous pulmonary surfactant is a complex mixture of phospholipid, neutral lipid and protein. Surfactant abnormalities are a feature of many respiratory diseases, including asthma [1]. In a pilot study exogenous surfactant administration significantly improved lung function in patients during an asthmatic attack [2]. The high surface pressure exerted by surfactant in conducting airways is a major force opposing airway oedema. Allergen-induced inhibition of this function in asthma may promote proteinaceous oedema and mucus plugging typical of the disease. Impaired surface-tension properties and altered phospholipid composition $24 \mathrm{~h}$ after local allergen challenge indicate a contribution of surfactant dysfunction to the late asthmatic response (LAR) in asthma [3]. While comparable changes of lesser magnitude are also evident in airway but not alveolar surfactant in stable asthma [4], a potential role for surfactant dysfunction in the early asthmatic response (EAR) to inhaled allergen has not been studied. Exogenous phospholipid surfactant, when administered to rats, significantly reduced the neural response to methacholine challenge, suggesting a role for exogenous surfactant on the irritant airway receptors [5]. Consequently, the authors reasoned if impaired surfactant function contributes to airway hyperresponsiveness, administration of exogenous surfactant should be protective. The aim of this study was to ascertain whether the inhaled administration of
Pumactant (Britannia Pharmaceuticals Ltd, Redhill, UK), a synthetic phospholipid-based surfactant containing dipalmitoyl phosphatidylcholine and egg phosphatidylglycerol (7:3 by weight), formulated as a novel, dry powder suitable for inhalation, could protect asthmatic subjects against allergeninduced bronchoconstriction.

\section{Materials and methods}

A randomised, single-blind, prospective, cross-over trial was conducted to evaluate the efficacy, safety and tolerability of inhaled Pumactant on the EAR and LAR in subjects with atopic asthma. A total of 14 nonsmoking, adult subjects with mild, atopic asthma were randomised into the study, of which 12 had evaluable data. During the course of the study, due to the mechanical failure of the dosing and delivery device, the first five subjects treated received a suboptimal dose of the study drug. The authors observed a degree of aggregation of Pumactant and therefore assumed that an unknown dose of the study drug had been delivered. Therefore, the study was temporarily suspended until the problem was rectified. The five subjects affected completed the study and the results of these subjects showed no consistent effect, indicating that either very small amounts or none of the study drug was 
delivered. Following the resolution of these problems, the clinical trial was restarted. Consequently, the data presented in this paper are of the seven subjects subsequently treated postmechanical failure, all of whom are reported in this study, and who had complete and evaluable data, and had received full doses of the study medication.

The study was approved by the local research ethics committee and all subjects gave their written, informed consent. The inclusion criteria were nonsmokers aged between 18-60 yrs, a history of mild, stable asthma without the use of systemic corticosteroids for at least 3 months prior to participation and a forced expiratory volume in one second (FEV1) of $\geqslant 70 \%$ predicted. All study subjects had a positive skin-prick test to an aeroallergen. The subjects underwent standard bronchialprovocation tests (BPT) [6] to the aeroallergen based on their skin-prick test results. Spirometry was recorded to establish a baseline FEV1 using a Vitalograph compact spirometer (Vitalograph Ltd, Maids Moreton, UK). After recording the baseline spirometry and ensuring that the subject was suitable to continue, the subject inhaled five breaths of nebulised, normal saline. Measurements of FEV1 were made at 5 and $10 \mathrm{~min}$ after saline inhalation. The highest FEV1 at $5 \mathrm{~min}$ and the highest at $10 \mathrm{~min}$ were noted and the lower of these was recorded as the postsaline baseline measurement. If the fall in FEV1 was $\leqslant 10 \%$ after saline inhalation, the first dose of allergen starting with 250 standard quality units $\cdot \mathrm{mL}^{-1}$ was administered through a dosimeter (Spira Electra; Spira Respiratory Care Centre, Hämeenlinna, Finland) and FEV1 recorded. After each concentration of allergen, a four-fold increment was administered providing the FEV1 had not fallen by $>10 \%$ from the postsaline value. If the fall in FEV1 was between $10-15 \%$, a two-fold increment was administered. If the fall was $>15 \%$ but $<25 \%$ from the postsaline baseline, the same dose was repeated. The challenge was terminated after a $25 \%$ fall in FEV1 was achieved and the subject was followed up for the next $10 \mathrm{~h}$ with repeated FEV1 measurements every $30 \mathrm{~min}$.

All included subjects had documented EAR and LARs, defined as decreases in FEV1 following the standard BPT with an allergen, to which they showed a positive skin-prick test reaction of $\geqslant 25 \%$ within $15 \mathrm{~min}$ (EAR) and $\geqslant 15 \%$ between 3-10 h (LAR).

Subjects received both Pumactant (PT) and no treatment (NT), in a randomised order, separated by at least a 3-week interval. Pumactant was formulated as a novel, micronised dry powder. Two administrations of Pumactant were given prior to exposure to the allergen BPT. The first was administered $8 \mathrm{~h}$ in advance and the second $30 \mathrm{~min}$ in advance. Each administration involved a single inhalation, following priming of each of the four 100-mg dose loadings of Pumactant powder into a purpose-built delivery device. Due to the nonavailability of suitable systems that could deliver such large doses of dry powder into the lungs, a dedicated, purpose-built system was designed, which could generate a cloud of Pumactant powder to achieve a fine particle dose of $25 \mathrm{mg}$ per inhalation. As Pumactant consists of a phospholipid, a wax-like substance that aggregates easily on exposure to moisture in the atmosphere, the device design was unusual as it incorporated a burst of air into a powder reservoir that forced the Pumactant through a mesh into a 4-L metal spacer. In order to reduce the loss of powder to the atmosphere, the spacer was previously evacuated to subatmospheric pressure. Subjects were requested to inhale from the spacer device from functional residual capacity to their total lung capacity followed by a breath-hold of $10 \mathrm{~s}$. The total effective respirable dose for each of the two administrations of Pumactant was $\sim 100 \mathrm{mg}$, verified by the in vitro Impactor system. Empty vials were used in the delivery device for NT in a single-blind fashion as no suitable placebo was available.
Statistical analyses were performed for the area under the curve (AUC) of FEV1 between 0-2 h (EAR) and 3-10 h (LAR) expressed as the percentage fall from the postsaline value. The AUC was calculated using the standard trapezoid rule and the results were analysed using analysis of variance appropriate for the cross-over designs.

\section{Results}

For the seven subjects, the mean \pm SD age was $29.6 \pm 11.0$ and baseline FEV1 was $85.7 \pm 9.2 \%$ pred.

Treatment with Pumactant virtually abolished the EAR to airway challenge with allergen (fig. 1). The mean \pm SEM AUC between $0-2 \mathrm{~h}$ (EAR) following BPT was $0.08 \pm 1.66 \%$ for PT and $13.29 \pm 4.28 \%$ for NT $(\mathrm{p}<0.01)$. The apparent high variability for PT treatment was due to FEV1 exhibiting a net increase for some individuals over this 2-h period. All of the seven subjects had no EAR to allergen BPT and the LAR was reduced (fig. 2). However, this did not reach statistical significance and the mean AUC between 3-10 h (LAR) for PT was $11.0 \pm 4.51 \%$ and for NT was $17.35 \pm 3.40 \%(\mathrm{p}=0.16)$. The maximum percentage reduction in FEV1 for the EAR was $4.19 \pm 1.57 \%$ with PT and $29.68 \pm 5.44 \%$ with NT $(\mathrm{p}<0.001)$. The maximum percentage reduction for the LAR was $23.98 \pm$ $6.79 \%$ with PT and $35.29 \pm 5.35 \%$ with NT $(\mathrm{p}=0.056)$ (table 1$)$.

The dose of Pumactant administered was well tolerated by all the subjects. Adverse events reported and classified were not severe, did not require treatment and were likely to be unrelated to study drug (table 2).

\section{Discussion}

The ability of a protein-free phospholipid-based surfactant to abolish the EAR in all seven subjects was both dramatic and unexpected. It provides the first direct evidence of a contributory role for surfactant therapy in acute asthmatic response. Previous studies have focused on the LAR response, where inhibition of surfactant function by oedema protein is thought to contribute to further airway oedema and mucus plugging [7]. The effects of Pumactant on the EAR may be due to immunomodulatory properties of surfactant phospholipid or due to nonspecific barrier function of the surfactant [8]. Any pre-existing underlying surfactant dysfunction in the larger airways [9] could be worsened by inhaled aeroallergens

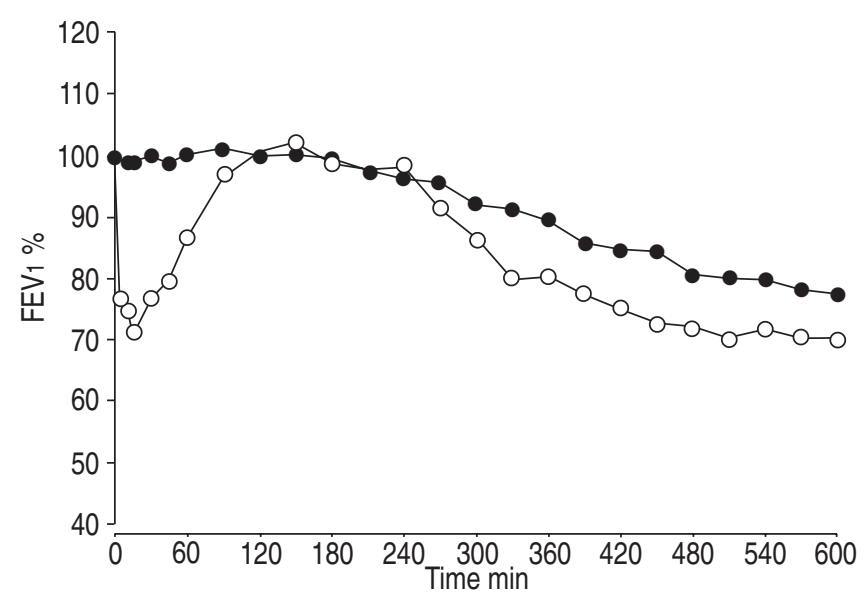

Fig. 1.- The forced expiratory volume in one second (FEV1) of subjects with (O) and without $(\bigcirc)$ Pumactant treatment. The treatment with Pumactant completely abolished the early asthmatic response to airway challenge with the allergen. 

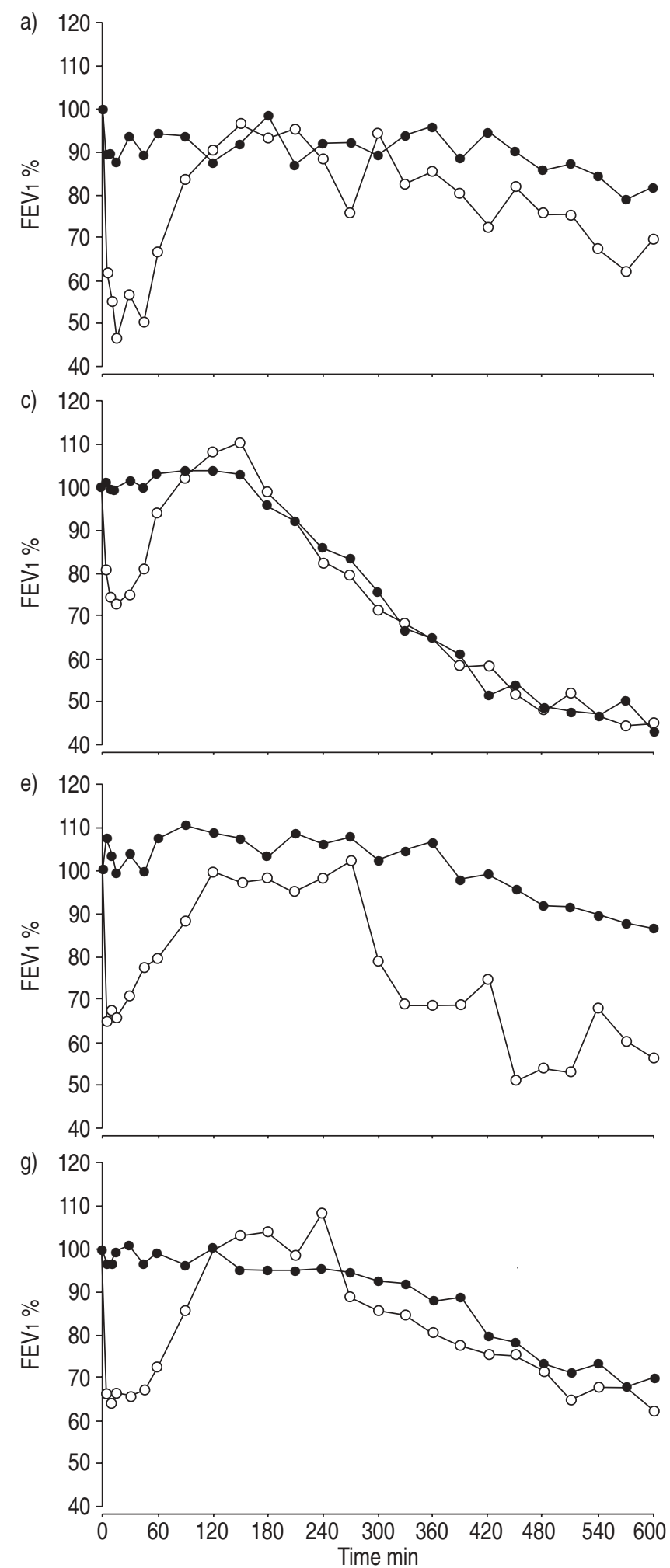

during acute asthma episodes. Supplementation with an exogenous surfactant could restore these abnormalities thereby improving airway function.

Previous animal studies have shown that exogenous-surfactant administration significantly reduces allergen-induced bronchoconstriction $[10,11]$. The only means of investigating this finding in humans is either by the administration of drugs that enhance surfactant synthesis or by the administration of exogenous surfactants. However, it remains to be seen whether b)

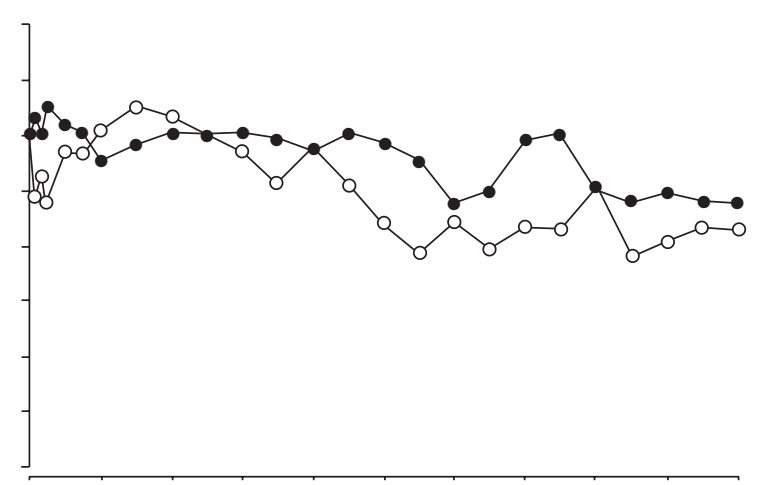

d)

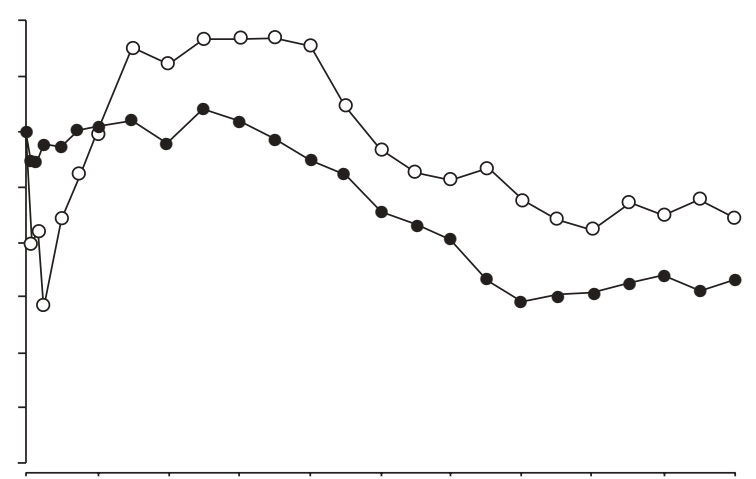

f)

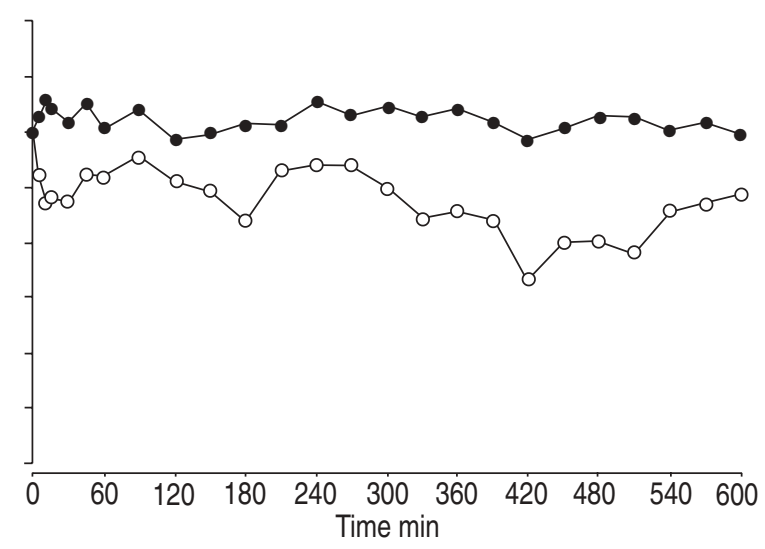

Fig. 2. - The forced expiratory volume in one second (FEV1) of the seven individual subjects $(1-7 ;$ a-g) with $(\bullet)$ and without $(\bigcirc)$ Pumactant treatment showing early and late asthmatic responses.

pharmacological stimuli can augment surfactant synthesis and secretion to clinically significant levels. Direct administration of an exogenous surfactant was the modality of choice. Therefore, the authors investigated the role of exogenous surfactant administration in patients with allergic asthma.

Since the exact amount of surfactant needed to be effective in adult asthmatics is not known and given the impracticalities of directly extrapolating neonatal doses for respiratory distress syndrome (a state of surfactant deficiency) to asthma 
Table 1.-Maximum percentage reduction in forced expiratory volume in one second (FEV 1 ) during early asthmatic response (EAR) and late asthmatic response (LAR) in each patient before (no treatment) and after treatment with Pumactant

\begin{tabular}{lccccc}
\hline \multirow{2}{*}{ Subject } & \multicolumn{2}{c}{ EAR } & & \multicolumn{2}{c}{ LAR } \\
\cline { 2 - 3 } \cline { 5 - 5 } & Pumactant & No treatment & & Pumactant & No treatment \\
& 12.4 & 53.6 & & 21.3 & 38.3 \\
1 & 4.8 & 12.0 & & 12.2 & 21.7 \\
2 & 0.4 & 27.1 & & 56.8 & 55.6 \\
3 & 5.5 & 31.3 & & 30.1 & 16.9 \\
4 & 0.8 & 35.4 & & 13.5 & 49.0 \\
5 & 1.5 & 12.9 & & 1.7 & 27.2 \\
6 & 3.9 & 35.5 & 32.3 & 38.3 \\
7 & & & &
\end{tabular}

Table 2. - Adverse events occurring to subjects during course of study

\begin{tabular}{lcc}
\hline Adverse event & Pumactant & No treatment \\
\hline Subjects n & 7 & 7 \\
Pustular rash & 1 & 0 \\
Viral infection & 1 & 0 \\
\hline
\end{tabular}

(a state associated with surfactant dysfunction), the selection dose of Pumactant was made according to practical limitations i.e the amount that could be delivered reasonably and inhaled safely. If the phospholipids are forming a physical barrier function, then a relative "excess" would be more appropriate in this pilot study, especially as inadequate dosing has been reported previously in other pilot trials of surfactant therapy in asthma [12]. In this study, Pumactant was administered as a novel dry powder through a purposebuilt inhalation device. Furthermore, there is evidence that a dry-powder formulation of surfactant would be more surface active on a weight for weight basis than a wet formulation [13]. Dosing at $8 \mathrm{~h}$ and $30 \mathrm{~min}$ prior to BPT administration was intended to ensure the presence of Pumactant on the lung surface both during the EAR and LAR.

While the precise mechanism by which Pumactant pretreatment abolished the early asthmatic response to inhaled allergen requires further study, this initial proof-of-concept study demonstrates the possibility that exogenous surfactant administration is clinically relevant. Moreover, the efficacy of this dry-powder, phospholipid surfactant, lacking surfactant proteins, strongly supports the concept that different formulations of therapeutic surfactants may be required to treat the differing underlying pathologies of various respiratory disease processes.

Acknowledgements. The authors would like to acknowledge A. Postle and B.A. Hills for their discussions related to the work presented, and $\mathrm{J}$. Thompson and M. Aydin for assistance with the delivery device.

\section{References}

1. Hohlfeld JM. The role of surfactant in asthma. Respir Res 2001; 3: 4-12.

2. Kurashima K, Ogawa H, Ohka T, Matsuda T, Kobayashi T. A pilot study of surfactant inhalation in the treatment of asthmatic attacks. Arerugi 1991; 40: 160-163.

3. Heeley EL, Hohlfeld JM, Krug N, Postle AD. Phospholipid molecular species of bronchoalveolar lavage fluid after local allergen challenge in asthma. Am J Physiol Lung Cell Mol Physiol 2000; 278: L305-L311.

4. Wright SM, Hockey PM, Enhorning G, et al. Altered airway surfactant phospholipid composition and reduced lung function in asthma. J Appl Physiol 2000; 89: 1283-1292.

5. Hills BA, Chen Y. Suppression of neural activity of bronchial irritant receptors by surface-active phospholipid in comparison with topical drugs commonly prescribed for asthma. Clin Exp Allergy 2000; 30: 1266-1274.

6. Chai H, Farr RS, Froehlich LA, et al. Standardization of bronchial inhalation challenge procedures. J Allergy Clin Immunol 1975; 56: 323-327.

7. Hohlfeld JM, Ahlf K, Enhorning G, et al. Dysfunction of pulmonary surfactant in asthmatics after segmental allergen challenge. Am J Respir Crit Care Med 1999; 159: 1803-1809.

8. Hills BA. Asthma: is there an airway receptor barrier? Thorax 1996; 51: 773-776.

9. Wilsher ML, Parker DJ, Haslam PL. Immunosuppression by pulmonary surfactant: mechanisms of action. Thorax 1990; 45: 3-8.

10. Becher G. Lung surfactant prevents allergic bronchial constriction in ovalbumin sensitized guinea pigs. Biomed Biochim Acta 1985; 44: K57-K61.

11. Richman PS, Batcher S, Catanzaro A. Pulmonary surfactant suppresses the immune lung injury response to inhaled antigen in guinea pigs. $J$ Lab Clin Med 1990; 116: 18-26.

12. Oetomo SB, Dorrepaal C, Bos H, et al. Surfactant nebulization does not alter airflow obstruction and bronchial responsiveness to histamine in asthmatic children. Am J Respir Crit Care Med 1996; 153: 1148-1152.

13. Hills BA. An alternative view of the role(s) of surfactant and the alveolar model. J Appl Physiol 1999; 87: 1567-1583. 